\title{
DESAIN SISTEM MANUFAKTUR MENGGUNAKAN ERP SYSTEM: SUATU PENDEKATAN PRAKTIS
}

\author{
Vincent Gaspersz ${ }^{*}$
}

\begin{abstract}
One of the manufacturing management systems that have been known internationally is Enterprise Resource Planning (ERP), but many people have not yet known about the ERP methodology and its application within manufacturing organizations.

This article provides in-depth knowledge of the ERP methodology and its application in manufacturing organizations. This article can be a useful reference for both manufacturing business scientists and practitioners or anyone who seeks for information on the implementation of ERP system in manufacturing organization.
\end{abstract}

Key words: Enterprise Resource Planning (ERP) System, manufacturing system

\section{PENDAHULUAN}

Proses industri harus dipandang sebagai suatu perbaikan atau peningkatan terus-menerus (continuous improvement), yang dimulai dari sederet siklus sejak adanya ide-ide untuk menghasilkan suatu produk, pengembangan produk, proses produksi, sampai distribusi kepada konsumen. Seterusnya, berdasarkan informasi sebagai umpan-balik yang dikumpulkan dari pengguna produk (pelanggan) itu, maka dapat dikembangkan ide-ide untuk menciptakan produk baru atau memperbaiki produk lama beserta proses produksi yang ada sekarang. Berkaitan dengan hal ini, maka manajemen sistem manufaktur akan memproses informasi yang berasal dari sistem manufaktur, pelanggan, dan lingkungan melalui proses manajemen untuk menjadi keputusan atau tindakan manajemen guna meningkatkan efektivitas dan efisiensi dari sistem manufaktur itu.

Sistem informasi manufakturing yang berkembang sekarang ini adalah Enterprise Resource Planning (ERP) yang menggabungkan sistem manufacturing resource planning (MRP II) dengan sistem akuntansi dan keuangan. Bagaimanapun, kalangan praktisi maupun ilmuwan dalam bidang manajemen industri di Indonesia, belum memahami secara komprehensif tentang metodologi dan aplikasi formal dari sistem ERP ini dalam perusahaanperusahaan industri manufaktur di Indonesia. Agar memperoleh pemahaman yang benar dan komprehensif tentang sistem ERP ini, maka artikel singkat ini dibuat menggunakan pendekatan praktis.

*) Konsultan Profesional dalam Manajemen Sistem Industri dan Kualitas serta Lektor Kepala pada Program Pascasarjana MM Universitas Trisakti, Jakarta. 


\section{TINJAUAN PUSTAKA}

\section{Konsep Sistem, Sistem Manufaktur, dan Manajemen Sistem Manufaktur}

Sistem adalah suatu kelompok elemen yang berinteraksi atau saling tergantung secara teratur yang membentuk satu kesatuan menuju pencapaian suatu tujuan (APICS, 1998; Nauhria and Prakash, 1995; Blanchard and Fabrycky, 1990).

Setiap sistem harus memiliki paling sedikit tujuh elemen yang saling bekerja sama agar mencapai tujuan dari sistem itu. Ketujuh elemen dari sistem itu adalah: (1) tujuan (objectives), (2) pelanggan (customers), (3) outputs, (4) proses-proses (processes), (5) inputs, (6) pemasok (suppliers), dan (7) pengukuran (measurements). Untuk memudahkan mengingat ketujuh elemen dari sistem itu, maka dapat disingkat berdasarkan akronim bahasa Inggris: SIPOCOM (Suppliers-Inputs-Processes-Outputs-Customers-Objectives-Measurements).

Keterkaitan ketujuh elemen sistem ini ditunjukkan dalam Gambar 1.

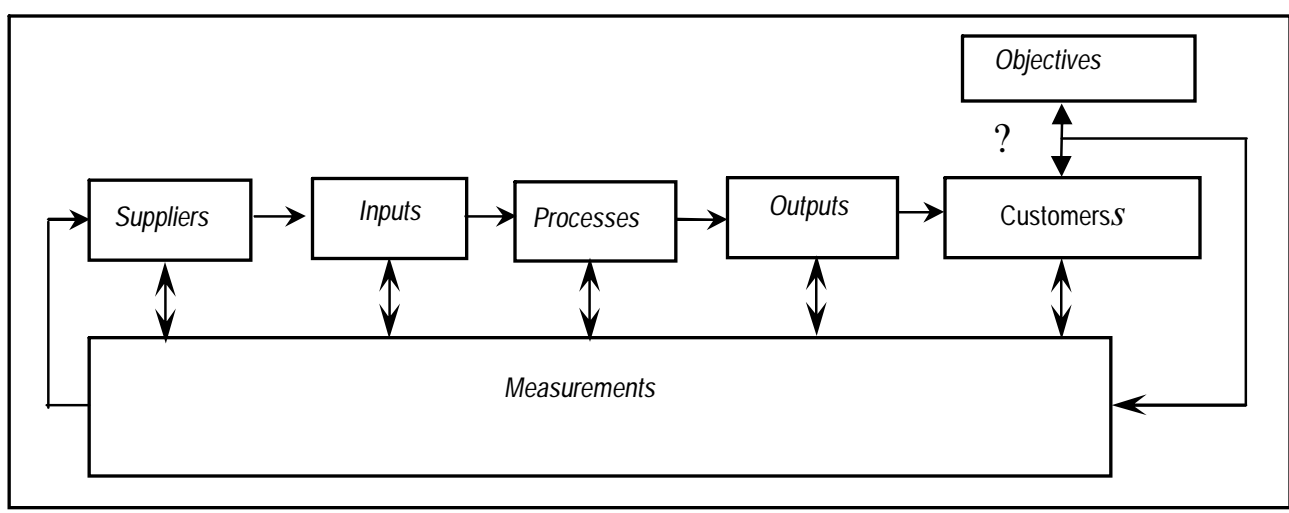

Gambar 1

Diagram Keterkaitan Elemen SIPOCOM dalam Sistem

Berdasarkan konsep umum tentang sistem di atas, maka dapat dibangun suatu sistem manufaktur dan manajemen sistem manufaktur. Manajemen sistem manufaktur terdiri dari dua konsep, yaitu: (1) konsep manajemen, dan (2) konsep sistem manufaktur. Suatu sistem manufaktur mengkonversi input yang berasal dari pemasok menjadi output untuk digunakan oleh pelanggan, sedangkan manajemen sistem manufaktur memproses informasi yang berasal dari sistem manufaktur, pelanggan, dan lingkungan melalui proses manajemen untuk menjadi keputusan atau tindakan manajemen guna meningkatkan efektivitas dan efisiensi dari sistem manufaktur itu. Konsep sistem manufaktur dan manajemen sistem manufaktur ditunjukkan dalam Gambar 2. 


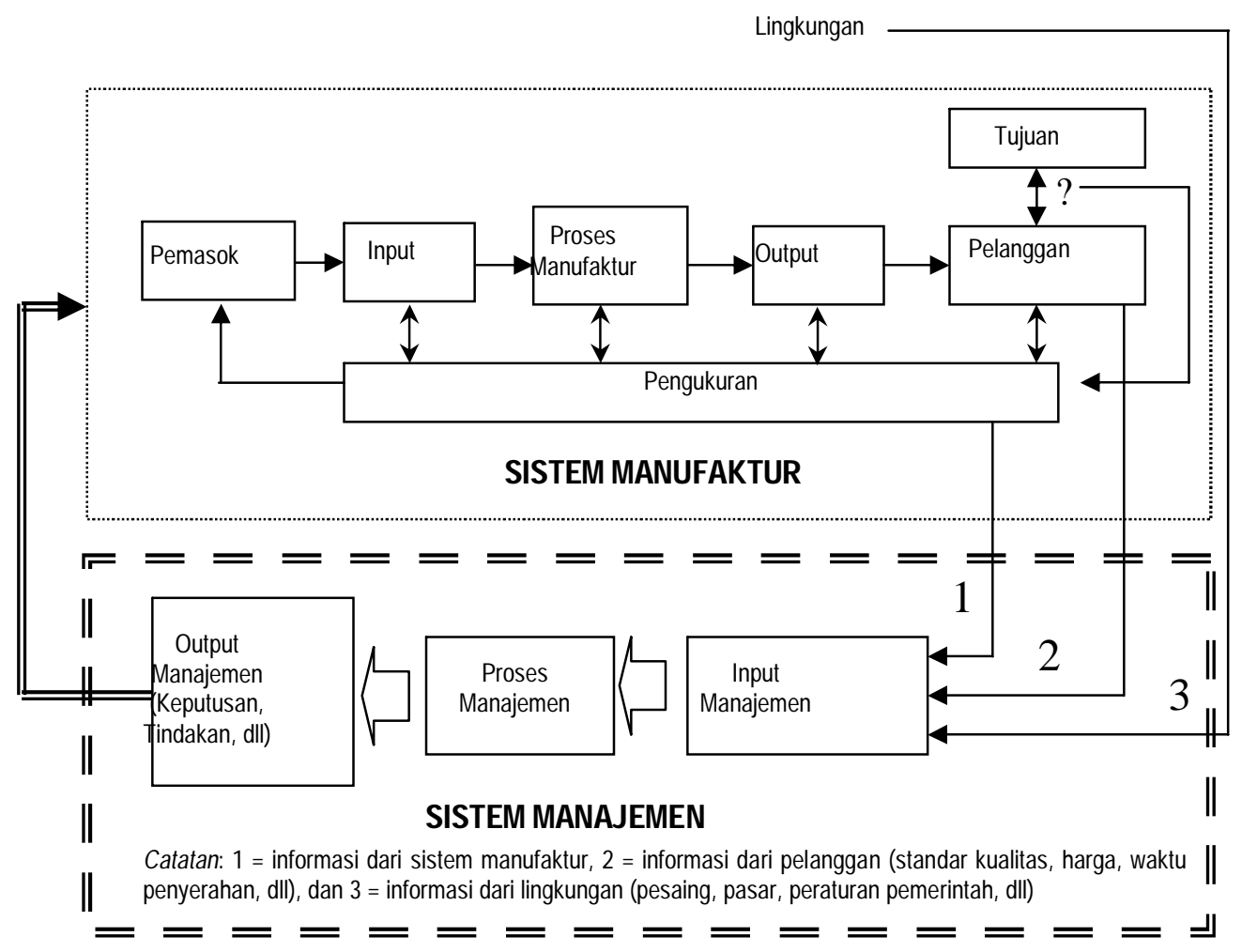

Gambar 2

Konsep Manajemen Sistem Manufaktur

\section{Strategi dan Kapabilitas Manufakturing Kelas Dunia}

Menurut Mabert and Jacobs (1991) dalam lingkungan yang dinamik, industri manufaktur kelas dunia memiliki empat tujuan utama, yaitu: (1) memproduksi produk-produk berkualitas tinggi, (2) mempertahankan penyerahan produk tepat waktu, (3) meningkatkan produktivitas agar menjadi kompetitif dalam harga produk, dan (4) memberikan suatu struktur manufakturing yang fleksibel.

Sistem manufaktur yang efektif dan efisien membutuhkan integrasi dari banyak subsistem yang mempengaruhi dan mengendalikan proses manufaktur, guna memberikan kemampuan perusahaan untuk mencapai empat tujuan di atas.

Berdasarkan kenyataan di atas, maka perusahaan-perusahaan manufaktur yang akan mendominasi pasar di abad ke-21 adalah perusahaan yang memiliki dedikasi total kepada pelanggan untuk memenuhi kebutuhan dan ekspektasi mereka. 
Schonberger and Knod (1994) menyatakan bahwa perusahaanperusahaan industri harus memiliki enam persyaratan agar mampu memenuhi kebutuhan dan ekspektasi pelanggan, yaitu: (1) menghasilkan produk berkualitas tinggi, (2) memiliki derajat fleksibilitas yang tinggi dalam hal perubahan volume dan spesifikasi produk, (3) memberikan tingkat pelayanan yang tinggi, (4) efisien dalam biaya produksi, (5) memiliki waktu tunggu yang pendek untuk memperoleh inovasi baru dan lebih baik dalam hal proses produksi dan memasuki pasar, dan (6) memiliki sedikit atau tanpa variabilitas dalam hal penyimpangan terhadap target.

Telah menjadi jelas bahwa kunci untuk memperoleh profitabilitas dan daya tahan dari industri manufaktur dalam pasar global yang hiperkompetitif, adalah kemampuan dari manajemen sistem manufaktur untuk menggunakan semua sumber daya yang tersedia guna meningkatkan efektivitas dan efisiensi dari sistem manufaktur itu, serta kemampuan mengintegrasikan teknologi yang tepat agar mencapai penggunaan modal dan fasilitas yang optimum dari industri manufaktur itu.

Tabel 1

Taksonomi dari Strategi Manufakturing

\begin{tabular}{|l|l|}
\hline \multicolumn{1}{|c|}{ Keunggulan Kompetitif } & \multicolumn{1}{c|}{ Kemampuan atau Kapabilitas } \\
\hline $\begin{array}{l}\text { Fleksibilitas } \\
\text { - Desain }\end{array}$ & $\begin{array}{l}\text { Membuat perubahan desain dan/atau memperkenalkan produk } \\
\text { baru secara cepat ke pasar } \\
\text { Respons terhadap perubahan dalam volume }\end{array}$ \\
\hline $\begin{array}{r}\text { Kualitas } \\
\text { - Colume }\end{array}$ & Menawarkan konsistensi kualitas \\
- Performance & Memberikan produk-produk dengan kinerja tinggi \\
\hline $\begin{array}{r}\text { Penyerahan } \\
\text { - Kecepatan } \\
\text { - Dependability }\end{array}$ & Menyerahkan produk secara cepat \\
\hline Harga kompetitif & Menawarkan produk tepat waktu (sesuai yang dijanjikan) \\
\hline Pelayanan purna jual & Memberikan pelayanan purna jual \\
\hline Broad line & Produce a broad product line \\
\hline
\end{tabular}

Sumber: Miller J. G. and Aleda Roth (1994) in Heizer J. and Barry Render (1996).

Suatu komitmen organisasional yang berdampak luas, seperti peningkatan terus-menerus (continuous improvement) untuk memenuhi enam persyaratan kapabilitas dan empat tujuan dari industri manufaktur kelas dunia di atas, disebut sebagai strategi. Dalam perumusan strategi organisasional, tiga elemen kunci harus dipertimbangkan, yaitu: (1) perusahaan, (2) pelanggan, dan (3) pesaing. Keberhasilan dari strategi yang dirumuskan akan memberikan kekuatan lebih kepada perusahaan dibandingkan pesaing-pesaingnya untuk memenuhi kebutuhan dan ekspektasi pelanggan. 
Miller and Roth (1994) dalam Heizer and Render (1996) telah mengembangkan strategi manufakturing agar mendukung suatu perusahaan manufaktur menjadi kompetitif dalam pasar global seperti ditunjukkan dalam Tabel 1.

PEMBAHASAN

Konsep Sistem Enterprise Resource Planning (ERP)

Agar industri manufaktur menjadi kompetitif dalam pasar global yang dinamik, maka industri itu membutuhkan sistem informasi terintegrasi yang mampu memberikan informasi secara komprehensif kepada manajemen untuk membuat keputusan-keputusan manajerial secara akurat. Dengan demikian melalui sistem informasi terintegrasi yang akurat dan proses manajemen manufaktur yang efektif, akan menghasilkan keputusan manajemen yang tepat untuk peningkatan terus-menerus dari sistem manufaktur itu. Dengan kata lain sistem informasi terintegrasi akan memberikan suatu keunggulan kompetitif bagi sistem manufaktur (lihat Gambar 2).

Suatu sistem informasi terintegrasi yang populer sekarang ini dalam industri manufaktur adalah sistem enterprise resource planning (ERP).

Sistem ERP merupakan sistem informasi berorientasi akuntansi (accounting-oriented information system) untuk mengidentifikasi dan merencanakan sumber-sumber daya lingkup perusahaan yang dibutuhkan guna memenuhi pesanan-pesanan pelanggan (customer orders). Sistem ERP merupakan sistem manajemen manufaktur berorientasi pelanggan (customer oriented manufacturing management system) (APICS, 1998; Dykstra and Cornelison, 1998).

ERP merupakan suatu proses perencanaan bisnis terintegrasi beserta eksekusinya guna mencapai fungsi-fungsi dari proses bisnis itu. ERP mengelola operasi dan fungsi-fungsi pendukung dari industri manufaktur dengan harus memperhatikan sumber-sumber daya kritis dari perusahaan.

Fungsi-fungsi perusahaan yang harus dilibatkan dalam suatu proses ERP adalah: perencanaan bisnis (visi, misi, dan perencanaan strategik), peramalan, proses MRP II (master planning, perencanaan produksi, pembelian, manajemen persediaan, pengendalian aktivitas, dan pengukuran kinerja manufakturing), finansial (payroll, penetapan biaya produksi, hutang, piutang, harta tetap, general ledger), sumber daya manusia, sistem informasi, rekayasa, pabrik dan peralatan, dan lain-lain.

MRP II atau perencanaan sumber daya manufakturing (Manufacturing Resource Planning) merupakan pusat dari ERP. Sebelum memahami tentang proses ERP perlu dijelaskan secara singkat tentang proses MRP II, karena MRP II merupakan bagian kunci dari ERP. Juga penting untuk dipahami bahwa ukuran-ukuran kinerja (performance measures) dari MRP II harus digunakan untuk aktivitas perencanaan bisnis dalam sistem ERP.

Proses perencanaan sumber daya manufakturing (MRP II) yang mencakup: perencanaan produksi, perencanaan kapasitas (rough-cut capacity planning), penjadualan produksi induk (MPS), perencanaan kebutuhan material (MRP), pembelian, manajemen persediaan, pengendalian aktivitas 
produksi, dan ukuran-ukuran kinerja ditunjukkan dalam Gambar 3, sedangkan proses ERP dalam sistem manufaktur ditunjukkan dalam Gambar 4.

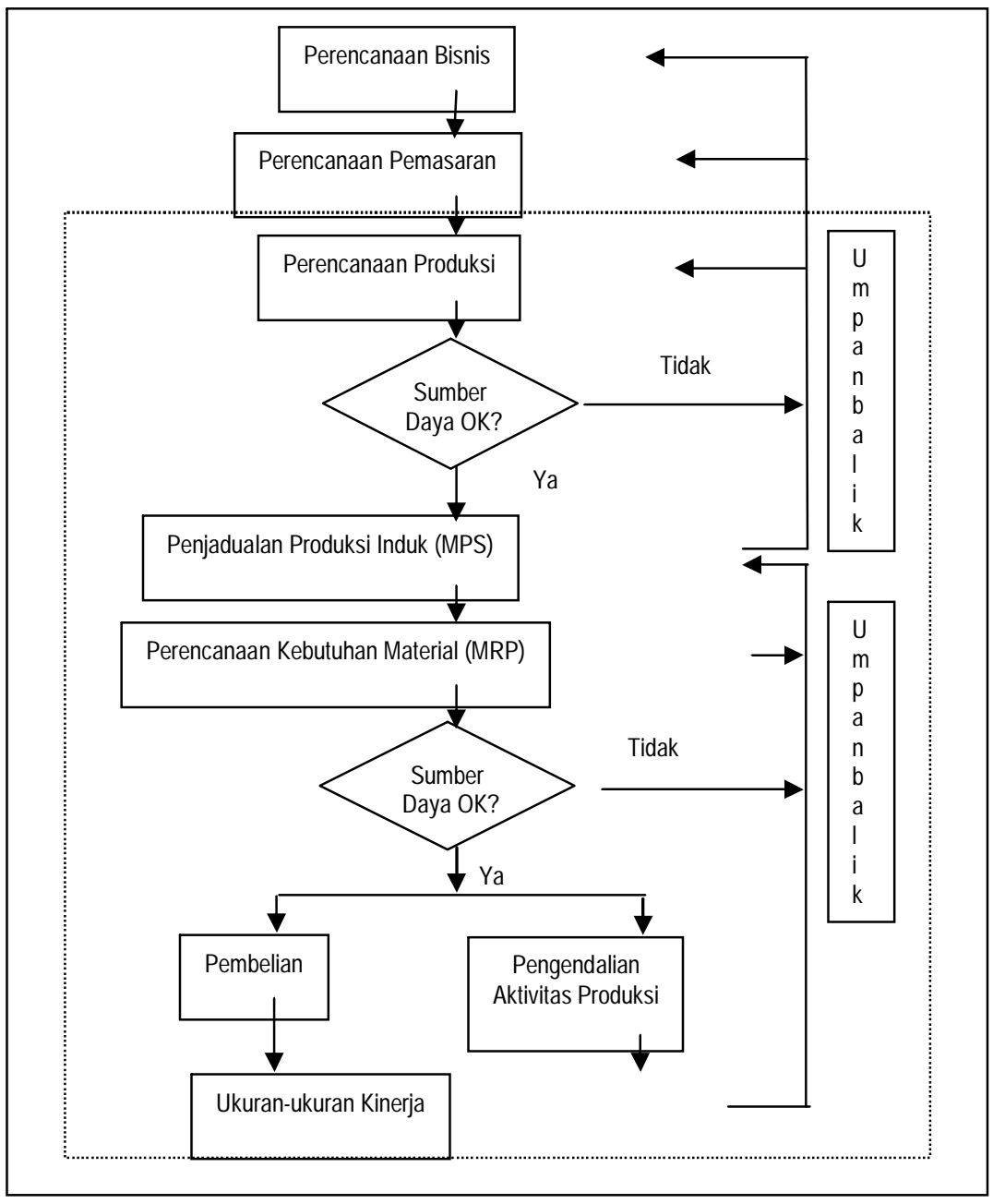

Gambar 3

Closed-loop Proses MRP II 


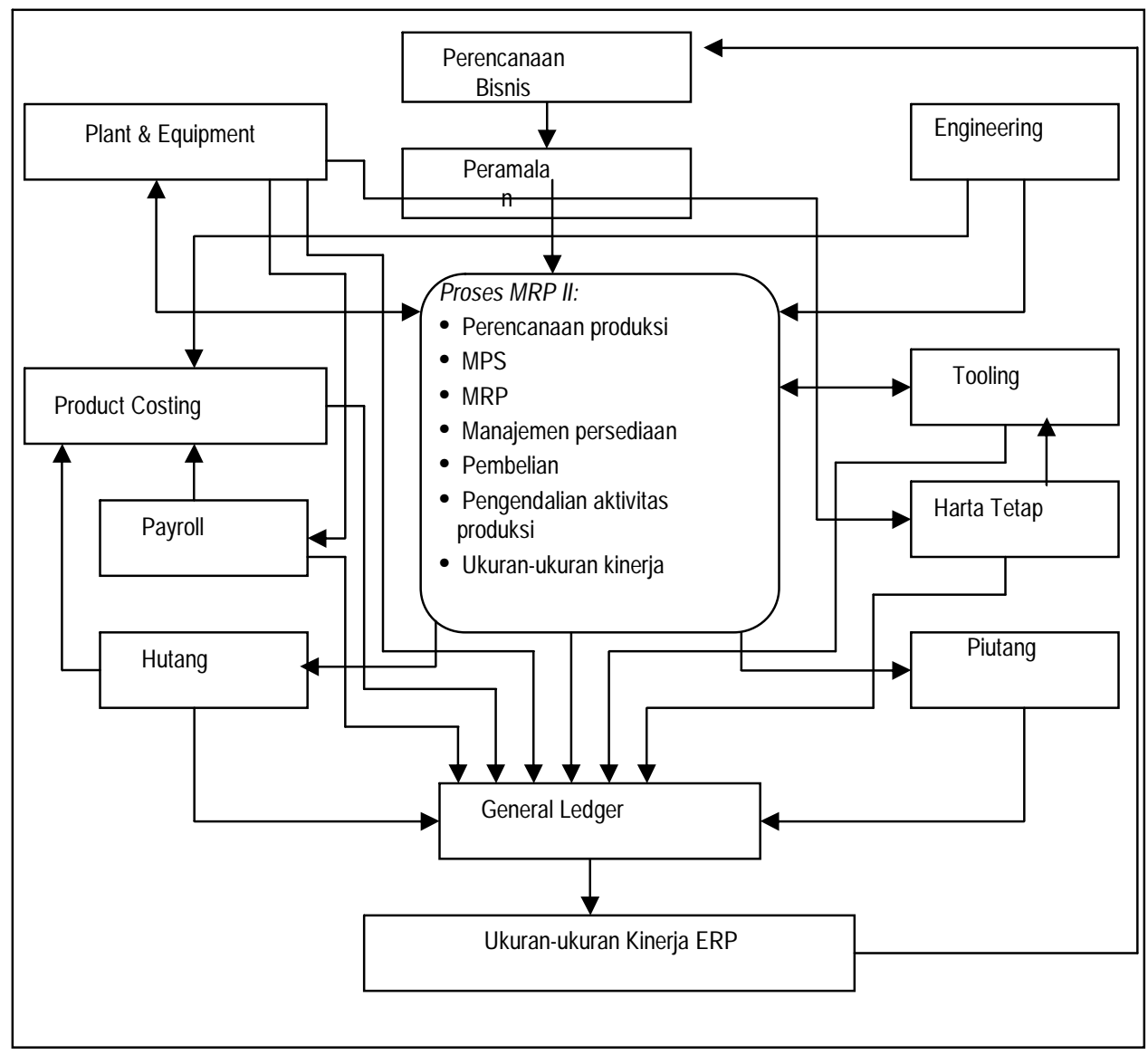

Gambar 4

Closed-loop Proses ERP sebagai berikut.

Dari Gambar 4 dapat dijelaskan mekanisme kerja dari sistem ERP

Perencanaan bisnis merupakan langkah pertama dari ERP dan merupakan landasannya. Perencanaan bisnis dimulai dengan penetapan pernyataan visi dan misi dari perusahaan. Pernyataan visi akan menjadi pedoman bagi stakeholders dalam mengelola perusahaan menuju ke masa depan yang diinginkan. Sedangkan pernyataan misi biasanya mendefinisikan secara garis besar tentang keberadaan dari perusahaan itu. Bentuk pernyataan umum dari suatu misi, misalnya: Misi dari perusahaan ini adalah memberikan produk berkualitas superior kepada pelanggan. Pernyataan misi biasanya berkaitan dengan pilihan produk dan pasar, jarang menyebutkan isuisu keuangan (Gaspersz, 2001). Setelah formulasi misi maka tujuan strategik 
ditetapkan untuk perusahaan itu. Tujuan strategik berfokus seputar sasaran pasar dan keuangan serta akan mencakup sasaran pengembangan produk dan sistem manufaktur. Tujuan keuangan mencakup Return On Investment (ROI), dan ukuran-ukuran profitabilitas lainnya. Tujuan pemasaran mencakup isu-isu seperti: pertumbuhan penjualan dan pangsa pasar, dan lain-lain. Tujuan pengembangan produk menyangkut tingkat kompleksitas desain produk, kandungan teknologi, fleksibilitas, biaya produksi, kualitas, dan lain-lain. Selanjutnya tujuan manufakturing berfokus pada cara-cara di mana sistem manufaktur itu akan memberikan suatu keunggulan kompetitif untuk perusahaan.

Peramalan dalam proses ERP mengikuti perencanaan bisnis. Aktivitas peramalan merupakan suatu fungsi bisnis yang berusaha memperkirakan penjualan dan penggunaan produk sehingga produk-produk itu dapat dibuat dalam kuantitas yang tepat. Dengan demikian peramalan merupakan suatu dugaan terhadap permintaan yang akan datang berdasarkan pada beberapa variabel peramal, sering berdasarkan data deret waktu historis. Peramalan menerima informasi dari perencanaan bisnis dan analisis penjualan, yang selanjutnya memberikan informasi kepada perencanaan produksi dan perencanaan keuangan.

Perencanaan sumber daya manufakturing (MRP II) merupakan bagian inti dari sistem ERP. MRP II menerima informasi dari peramalan (forecasting), pemasukan pesanan (order entry), rekayasa (engineering), dan plant \& equipment maintenance; selanjutnya MRP II memberikan informasi kepada hutang (accounts payable), piutang (accounts receivable) pengiriman (shipping), perencanaan bisnis, dan fungsi-fungsi lain dari perusahaan. Ukuran-ukuran kinerja dari MRP II yang dipadukan dengan ukuran-ukuran kinerja ERP harus digunakan dalam aktivitas perencanaan bisnis.

Akuntansi dan keuangan juga merupakan bagian inti dari sistem ERP. Fungsi-fungsi seperti payroll, product costing, hutang (accounts payable), piutang (accounts receivable), harta tetap (fixed assets), dan general ledger berperanan penting dalam perencanaan keuangan guna mendukung sistem ERP. Payroll melakukan pembayaran untuk tenaga kerja langsung dan tidak langsung, di mana informasi ini diterima dari shop floor reporting, kemudian informasi itu diberikan kepada product costing dan general ledger. Product costing mencatat dan melaporkan biaya-biaya tenaga kerja, material, dan overhead yang terkait dengan pembuatan produk. Informasi ini diterima dari payroll dan shop floor reporting, yang selanjutnya informasi itu diberikan kepada general ledger. Hutang (accounts payable) mencatat dan melaporkan hutang perusahaan, di mana informasi ini diterima dari bagian pembelian dan selanjutnya memberikan informasi itu kepada product costing dan general ledger. Piutang (accounts receivable) mencatat dan melaporkan piutang perusahaan, di mana informasi ini diperoleh dari sales order processing and shipping, dan selanjutnya memberikan informasi itu kepada sales analysis/reporting, customer service, dan general ledger. Harta tetap (fixed assets) mencatat dan melaporkan harta perusahaan seperti bangunan, mesin dan peralatan, kendaraan, komputer, dan lain-lain, di mana informasi ini biasanya diperoleh dari bagian pembelian, serta informasi itu diberikan kepada general ledger. 
Perencanaan kebutuhan tooling (alat-alat seperti pisau, obeng, kunci-kunci, dil) untuk produksi juga merupakan komponen dari sistem ERP. Banyak perusahaan manufaktur yang melakukan perencanaan material secara baik, namun sedikit atau tidak ada yang melakukan perencanaan tooling berkaitan dengan jenis dan jumlah alat-alat yang dibutuhkan. Jenis alat-alat untuk menjalankan produksi termasuk masa pakai dari alat itu dicatat dalam Routing pada operasi di mana alat itu dibutuhkan. Persediaan dan lokasi penyimpanan dari alat-alat harus dipelihara atau dijaga dengan baik. ERP akan memberikan informasi berupa time-phased Net Tooling Requirements reporting, serupa dengan materials requirements reporting. Komponen tooling dari ERP menerima informasi dari MPS, manajemen persediaan, dan harta tetap, yang selanjutnya memberikan informasi kepada production scheduling, pembelian, dan general ledger.

Pemeliharaan dari plant \& equipment juga merupakan komponen dari ERP. Dalam sistem ERP, Plant and equipment maintenance menerima informasi dari production scheduling, manajemen persediaan, pembelian, dan accounts payable, serta memberikan informasi kepada payroll, harta tetap, dan general ledger.

Rekayasa (engineering) juga merupakan komponen dari ERP. Informasi tentang rekayasa disimpan melalui bills of material (BOM) dan routings. Engineering changes dikoordinasikan dengan material dan manufakturing, yang dikendalikan oleh suatu Engineering Change Notice (ECN) number, date, and/or product serial number. Engineering memberikan informasi kepada routings, bills of material (BOM), pembelian, dan product costing.

Berdasarkan penjelasan tentang mekanisme kerja dari ERP di atas, tampak bahwa banyak informasi yang saling berhubungan dari suatu perusahaan manufaktur yang diintegrasikan melalui ERP. Dengan demikian sistem ERP yang baik akan memberikan informasi komprehensif dan terintegrasi yang berguna untuk komunikasi di antara orang-orang dalam sistem manufaktur itu, serta memudahkan manajemen industri manufaktur untuk mengambil tindakan atau membuat keputusan tepat waktu dalam mencapai tujuan-tujuan perusahaan. Melalui komunikasi yang baik juga akan meningkatkan keharmonisan kerjasama antardepartemen dalam perusahaan manufaktur itu. Perlu dicatat bahwa terdapat dua mekanisme umpan-balik dalam sistem ERP (lihat Gambar 3 dan Gambar 4). Pertama, adalah ukuran-ukuran kinerja dari proses MRP II untuk perencanaan bisnis, dan kedua, adalah informasi keuangan dan ukuran-ukuran kinerja dari general ledger untuk perencanaan bisnis. Dengan demikian menjadi jelas bahwa ERP merupakan suatu proses perencanaan bisnis terintegrasi dari sistem manufaktur melalui memperhatikan sumber-sumber daya kritis dari perusahaan.

\section{Implementasi Sistem ERP dalam Industri Manufaktur}

Meskipun pada saat ini ERP hanya populer sebagai suatu software system untuk perusahaan manufaktur seperti: SAP R/3 Enterprise Resource Planning, SAP R/3 Financials, SAP R/3 Human Resources, SAP R/3 Logistics (lihat www.sap.com, Chase et. al., 1998), namun di masa mendatang sistem 
ERP akan menjadi suatu proses bisnis manufaktur yang handal. Di masa mendatang ERP akan menjadi sistem perencanaan bisnis terintegrasi beserta proses eksekusi untuk mengelola fungsi-fungsi operasional dan pendukung dari suatu perusahaan manufaktur.

Berdasarkan studi yang dilakukan oleh PRTM (uww.prtm.com), suatu perusahaan konsultasi manajemen, menunjukkan perkembangan penerapan ilmu pengetahuan dan teknologi modern dalam bisnis manufaktur di Amerika Serikat, sebagai berikut:
口 1970-1981 : Zero inventory and material requirements planning (MRP)
口 1984-1993: Total quality management (TQM), Just-in-Time (JIT) manufacturing and manufacturing resource planning (MRP II)
口 1997and : Integrated supply chains and the realization of ERP beyond implementations

Dari berbagai studi tentang keberhasilan implementasi sistem ERP dalam industri manufaktur (Marshall and Uzkan, 1999; Schindler and Conant, 1999), diketahui bahwa terdapat beberapa faktor kritis yang perlu diperhatikan oleh manajemen, yaitu:

1. Implementasi sistem ERP harus terintegrasi dengan usaha desain ulang proses bisnis (business process redesign) serta memposisikan sebagai suatu isu bisnis strategik.

2. Membentuk tim kerja lintas fungsional (cross-functional team) berdedikasi tinggi yang terdiri dari orang-orang terbaik yang berasal dari berbagai fungsi dalam organisasi.

3. Menjamin terdapat sistem komunikasi serta komitmen untuk memberikan tanggapan cepat terhadap isu-isu yang muncul dalam proses implementasi sistem ERP.

4. Memperhatikan aspek-aspek yang berkaitan dengan sumber daya manusia melalui manajemen perubahan (change management).

5. Menganggap bahwa implementasi ERP adalah bersifat massive, companywide, multidimensional, complex business change effort, bukan semata-mata implementasi paket software komputer.

Proses implementasi ERP tidak hanya berhenti sampai selesainya instalasi software komputer, tetapi harus dilanjutkan dengan optimasi proses secara terus-menerus agar mencapai tujuan perusahaan seperti: pertumbuhan (growth), ketangkasan (agility), dan kemampuan menciptakan keuntungan (profitability). Semua ini akan tergantung pada efektivitas dari manajemen sistem, karena kekuatan dari suatu sistem manufaktur sangat tergantung pada manajemen dari sistem manufaktur itu. Proses implementasi ERP secara bertahap ditunjukkan dalam Gambar 5. 


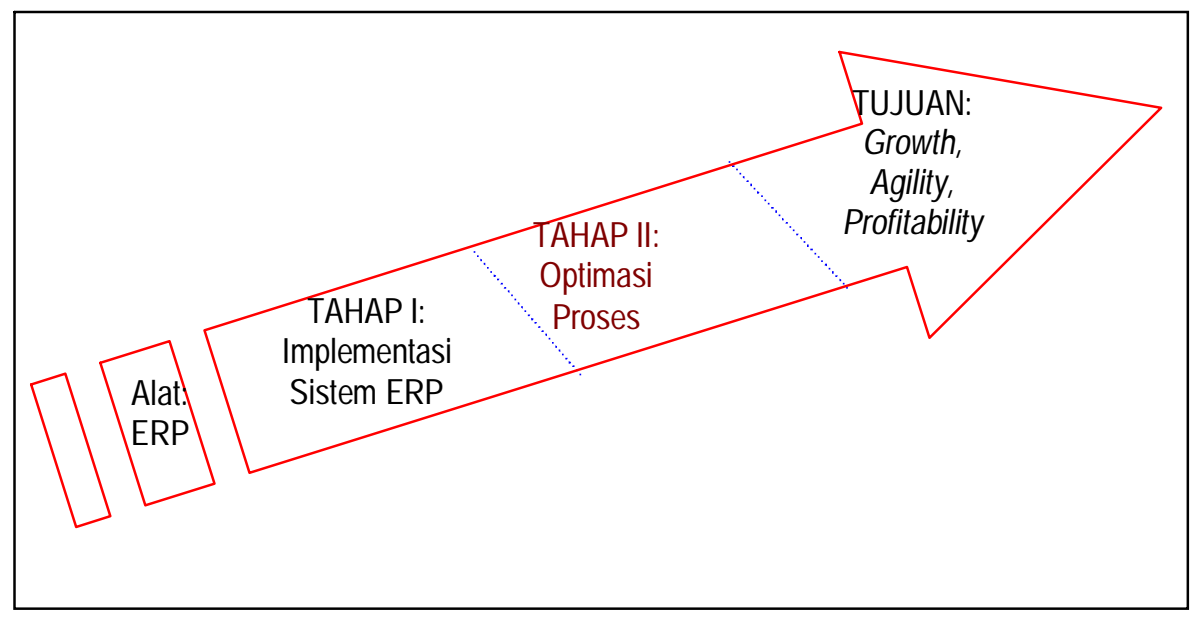

Gambar 5

Proses Implementasi Sistem ERP dalam Industri Manufaktur

\section{KESIMPULAN DAN REKOMENDASI}

Sitem Enterprise Resource Planning (ERP) mengintegrasikan banyak informasi yang saling berhubungan, terutama informasi yang berasal dari lantai pabrik (shop floor) dengan informasi akuntansi dan keuangan, sehingga akan memberikan informasi komprehensif dan terintegrasi yang berguna untuk komunikasi di antara orang-orang dalam sistem manufaktur itu, serta memudahkan manajemen industri manufaktur untuk mengambil tindakan atau membuat keputusan tepat waktu dalam mencapai tujuan-tujuan perusahaan. Melalui komunikasi yang baik juga akan meningkatkan keharmonisan kerjasama antardepartemen dalam perusahaan manufaktur itu.

Bagaimanapun, proses implementasi ERP tidak hanya berhenti sampai selesainya instalasi software komputer, tetapi harus dilanjutkan dengan optimasi proses secara terus-menerus agar mencapai tujuan perusahaan seperti: pertumbuhan (growth), ketangkasan (agility), dan kemampuan menciptakan keuntungan (profitability). Semua ini akan tergantung pada efektivitas dari manajemen sistem, karena kekuatan dari suatu sistem manufaktur sangat tergantung pada manajemen dari sistem manufaktur itu dan kualifikasi sumber daya manusia yang menempati posisi manajemen. Dengan demikian perlu direkomendasikan agar implementasi sistem ERP menggunakan pendekatan "cross-functional team" yang melibatkan semua departemen fungsional dalam organisasi manufaktur itu. 


\section{DAFTAR PUSTAKA}

APICS. 1998. "APICS Dictionary", 9th ed., APICS-The Educational Society for Resource Management, Wisconsin.

Blanchard, B. S. and Fabrycky, W. J. 1990. "Systems Engineering and Analysis", $2^{\text {nd }}$ ed., Prentice-Hall International, Singapore.

Chase, R. B, Aquilano, N. J, and Jacobs, F. R. 1998. "Production and Operations Management-Manufacturing and Services", $8^{\text {th }}$ ed., McGraw-Hill, Boston.

Dykstra, I. And Cornelison, R. G. 1998. "ERP—It's MRP and More!", 1998 APICS International Conference and Exposition, pp. 50-52.

Gaspersz, Vincent. 2001. "Production Planning and Inventory ControlBerdasarkan Pendekatan Sistem Terintegrasi MRP II dan JIT Menuju Manufakturing 21", Edisi Revisi dan Perluasan., Gramedia, Jakarta.

Heizer, J. and Render, B. 1996. "Production and Operations ManagementStrategic and Tactical Decisions", $4^{\text {th }}$ ed., Prentice-Hall, New Jersey.

Mabert, V. A. and Jacobs, F. R. 1991. Integrated Production Systems-Design, Planning, Control, and Scheduling", 4th ed., Industrial Engineering and Management Press, Institute of Industrial Engineers, Georgia.

Marshall, B. A. and Uzkan, S. 1999. "If ERP is the Solution, What Is the Problem? A Practitioner's Approach to Building a New Business Model", 1999 APICS International Conference Proceedings, pp. 473-476.

Nauhria, R. N. and Prakash, R. 1995. "Management of Systems", Wheeler Publishing, New Delhi.

Schindler, B. W. and Conant, J. M. 1999. "Successful ERP Implementation", 1999 APICS International Conference Proceedings, pp. 479-481.

Schonberger, R. J. and E. M. Knod, Jr. 1994. "Operations ManagementContinuous Improvement", $5^{\text {th }}$ ed., Richard D. Irwin, Illinois. 